\title{
THE ISOLATION OF CHROMOGENIC MYCOBACTERIA FROM LARYNGEAL CULTURES
}

\author{
BY \\ MIKLÓS LÁNYI \\ 'From the University Medical School, Budapest
}

(RECEIVED FOR PUBLICATION MARCH 22, 1957)

It is known that the cultural characteristics of strains of Mycobacterium tuberculosis isolated from tuberculous secretions may be changed under the influence of anti-tuberculosis drugs. It has been suggested that this is due to " biological disintegration" of the bacteria (Lányi and Eidus, 1954). The process is usually a gradual one. The present report is concerned with the isolation from laryngeal swabs of a number of atypical chromogenic strains of mycobacteria presumed to be disintegrated tubercle bacilli.

\section{Source of Strains}

In the routine culture for tubercle bacilli of 2,620 laryngeal swabs, atypical, chromogenic strains of mycobacteria were isolated on 16 occasions. The strains came from 16 patients, all suffering from pulmonary tuberculosis, and in 13 typical tubercle bacilli had been repeatedly isolated from previous swabs. Three of the patients appeared to have regressive infiltrative lesions, and the others, including nine with bilateral haematogenous apicosclerosis, suffered from chronic fibrosis. Thus the pathological condition was that seen in patients with a good immunity, and the clinical condition of all was satisfactory. The patients had been treated by chemotherapy, and the average dose received was 24.4 g. isoniazid, 827 g. P.A.S., and 32.8 g. streptomycin.

\section{Characteristics of Atypical Mycobacteria}

The strains caused a brownish discoloration on liquid lyophilized bovine plasma medium (Kováts, Eidus, and Lányi, 1955) and their colonies were easily shaken apart and settled down slowly. On Löwenstein medium the strains produced smooth, dysgonic colonies, which formed yellow, orangered or brownish-red pigments. Pigment production increased in daylight. Cultures on glycerinefree solid medium grew more abundantly. The primary culture period was $24-28$ days at an optimal temperature of $37^{\circ} \mathrm{C}$. They failed to grow on simple agar or broth media. All strains were resistant to $10 \mu \mathrm{g}$. per $\mathrm{ml}$. isoniazid.

The organisms were Gram-positive, acid-fast bacilli, showing many granules and placed in cord formation, similar to typical tubercle bacilli. They gave a positive neutral red test but were catalase negative.

Subcutaneous inoculation of guinea-pigs with $0.5 \mathrm{mg}$. wet weight caused a slight local reaction only, without spread, but the animals became tuberculin positive.

\section{Discussion}

Chromogenic acid-fast bacilli have been isolated from human sources by many authors. Some of these bacilli appeared to be quite different from tubercle bacilli and caused only benign local lesions (Linell and Nordén, 1954; Wells, Agius, and Smith, 1955). In other cases the strains were isolated from patients with atypical pulmonary lesions (Buhler and Pollak, 1953; Ostry, Kubin, et al., 1956 ; Wood, Buhler, and Pollak, 1956; Young, 1955). The pathogenic significance of these strains in man has already been discussed (Tarshis, 1956; Tarshis, Weed, Parker, and Dunham, 1955 ; Tarshis and Frisch, 1952 ; Timpe and Runyon, 1954), and it appears that those strains which are resistant to isoniazid are not pathogenic (Middlebrook, Cohn, and Oestreicher, 1955). Wilson and Morton (1956) described 46 atypical non-pathogenic acid-fast bacilli, but only nine were chromogenic and not all the patients from whom the strains were isolated had received chemotherapy.

The chromogenic strains recorded in this paper differ in many respects from saprophytic mycobacteria. Moreover, laryngeal swabs are not usually contaminated with saprophytic acid-fast bacilli. It is, therefore, presumed that these strains, isolated from patients with a good immunity after chemotherapy, represent dis- 
integrated tubercle bacilli. It is possible that a state of equilibrium is reached between these disintegrated mycobacteria and the host.

\section{REFERENCES}

Buhler, V. B., and Pollak, A. (1953). Amer. J. clin. Path., 23, 363. Kováts, F., Eidus, L., and Lányi, M. (1955). Rev. Tuberc. (Paris), ser. $5,19,59$.

L ányi, M., and Eidus, L. (1954). Schweiz. Z. Tuberk., 11, 447.

Linell, F., and Nordén, A. (1954). Acta tuberc. scand., Suppl. 33.
Middlebrook, G., Cohn, M. L., and Oestreicher, R. (1955). Rev. Tuberc., 72, 693.

Ostry, P., Kubin, M., et al. (1956). Rozhl. Tuberk., 16, 233.

Tarshis, M. S. (1956). Amer. Rev. Tuberc., 73, 601.

and Frisch, A. W. (1952). Ibid., 65, 278, 289, 302.

Weed, W. A., Parker, M. V., and Dunham, W. B. (1955). Ibid $\frac{0}{\bar{c} .}$

72, 119 .

Timpe, A., and Runyon, E. H. (1954). J. Lab. clin. Med., 44, 202. Ф

Wells, A. Q., Agius, E., and Smith, N. (1955). Amer. Rev. Tuberco 72, 53 .

Wilson, G. C., and Morton. D. E. (1956). Ibid., 73, 351.

Wood, L. E., Buhler, V. B., and Pollak, A. (1956). Ibid., 73, 917.

Young, R. D. (1955). Lancet, 2, 750. 